\title{
Geometria espiral aplicada no espaço: o caso do Museu Nacional de Arte Ocidental (1959)
}

\author{
Spiral geometry applied in space: the \\ case of the National Museum of Western \\ Art (1959)
}

\author{
Mariana Caldas \\ Estudante de Arquitetura e \\ Urbanismo / UNICAP \\ Recife, Brasil \\ mariana.slcaldas@gmail.com
}

\section{Ana Luisa Rolim \\ Arquiteta e Urbanista Professora Assistente III / Doutoranda MDU/UFPE ana.rolim@unicap.br}

\begin{abstract}
RESUMO:
Este artigo tem como objetivo discutir as peculiaridades da geometria da espiral, particularmente suas implicações quando aplicadaao desenhodo espaço. Utiliza-se como casoo Museu Nacional de Arte Ocidental, projetode Le Corbusier, inaugurado em 1959, que representa a materializaçãodas ideias do arquiteto referentes àconfiguração espacial em forma de espiral para espaços voltados à exposição de obras de arte. A base teórica empregada éa sintaxe espacial (HILLIER; HANSON, 2003; HILLIER, 1986)e sua instrumentalização por meio de análises de linhas axiais e espaços convexos,visando aferirem que medida a configuração do espaço pode influenciar na experiência do usuário do ponto de vista de seu movimento e visibilidade no espaço. Como contribuição, espera-se ampliar, de um modo geral, o entendimentode soluções utilizadas na arquitetura moderna e, especificamente, das propriedades que o percurso espiralar atribuiu ao espaço do museu.
\end{abstract}

Palavras-chave: Espiral; Sintaxe Espacial; Le Corbusier; Museus de arte.

\begin{abstract}
:
This paper aims to discuss the peculiarities of the spiral geometry, particularly its implications when applied to the design of built environments. The case study we present is the National Museum of Western Art, which was designed by Le Corbusier, opening its doors in 1959. The museum represents the materialization of the architect's ideas regarding the spatial configuration in the form of a spiral applied to art museums. We adopt the space syntax theory (HILLIER and HANSON, 2003; HILLIER, 1986) and its instrumentalization through axial lines and convex spaces analyses to verify the extent to which the spatial configuration might influence the visitor's experience from the point of view of their movement and visibility in space. As a contribution, in a broad spectrum, we hope to cast light on the understanding of design solutions employed in modern architecture and, specifically, the spatial attributes related to the museum's spiralling layout.
\end{abstract}

Keywords: Spiral; Space Syntax; Le Corbusier; Art Museums 


\section{INTRODUÇÃO}

O objetivo deste estudo é analisar espacialmente a aplicação da geometria espiral na arquitetura, utilizando a teoria da lógica social do espaço ou sintaxe espacial (HILLIER; HANSON,1984; HILLIER, 1986). Será discutido aqui, especificamente através de análise configuracionais, o Museu Nacional de Arte Ocidental (MNA0), em Tóquio (Le Corbusier, 1957-59), por ser um dos três principais projetos de museu pensados pelo arquiteto francosuíço, que segue o conceito inspirado no crescimento em espiral das conchas marinhas, proposto inicialmente para o Museu de Crescimento Ilimitado (MCI), de 1939, no qual o princípio é adaptado a uma malha ortogonal, sugerindo a circulação de visitação nas galerias a partir de um percurso em espiral (BAKER, 1998).

No campo teórico, a arquitetura pode ser estudada a partir de suas causas (determinações ambientais, políticas, ideológicas etc.), isto é, como uma variável dependente, ou de se seus efeitos, ou seja, com base em seus impactos diretos nos usuários (funcionais, econômicos, sociológicos, bioclimáticos etc.), o que implica em ser tomada como variável independente. A partir desta última postura, adota-se neste artigo a teoria da sintaxe espacial, cuja investigação baseia-se em que medida a arquitetura e o urbanismo interferem nas relações sociais.

Como estudo de caso, tem-se um projeto emblemático de Le Corbusier, um dos maiores arquitetos do século $\mathrm{XX}$, que, ainda na primeira metade do século XX, com o MCI e, posteriormente, o MNAO, pensa o espaço arquitetônico a partir de uma matriz geométrica específica: a espiral. Esta maneira de projetar, de certo modo, antecipa aproximações contemporâneas no campo da arquitetura que a abordam a partir da geração da forma ou do desenho generativo. Portanto, vê-se como de suma importância buscar maior entendimento acerca desta solução moderna, para, inclusive, ampliar seu potencial de reinterpretação e reutilização na contemporaneidade.

No campo da sintaxe espacial, espaços são vazios e estes são definidos por obstruções que restringem acesso e ocluem a visão. Sintaticamente, edifícios possuem uma série de espaços e cada espaço está conectado a outros. As obstruções podem ter um significado social e implicam no comportamento do habitat humano. Neste estudo, pretende-se investigar como no museu, definido como um tipo de espaço inicialmente contínuo e que segue uma narrativa, esta configuração em espiral influencia o movimento, o sentido de copresença e possíveis encontros por parte de visitantes.

Começamos definindo a espiral matematicamente, como uma curva plana que gira em torno de um ponto central, para contextualizá-la no projeto do Museu Nacional de Arte Ocidental (MNAO) de acordo com o partido utilizado e sua organização espacial, definindo o eixo de análise. A seguir, tem-se a análise sintática propriamente dita, que se utiliza de alguns meios de representação sintática, como mapas axiais, de visibilidade e convexos, de 
modo a avaliar as intenções projetuais para, então, chegarmos a algumas conclusões.

\section{ESPIRAL}

\subsection{Na natureza: a origem da forma}

$\mathrm{Na}$ matemática, a geometria é o ramo que estuda as formas que repetem-se em padrões semelhantes em fenômenos orgânicos e inorgânicos. Encontrados na natureza, os padrões de formas criados são um processo imposto pelas leis universais, podendo ser ou não uma convenção útil da mente. Portanto, a existência na geometria não quer dizer a real existência da forma na natureza, pois a matemática trabalha com pressuposições em torno disso, muitas vezes apresentando hipóteses probabilísticas (COOK, 1914).

Estas formas inicialmente encontradas na natureza podem apresentar regularidades, círculos, espirais, recorrências angulares, planos, simetrias e paralelismo, e formar certos padrões por sua ocorrência e propriedades específicas (COOK, 1914). Devido à junção da geometria com a física e a biologia, permite-se chegar à identificação de variadas ocorrências morfológicas, como as arborescentes, circulares, fractais, hexagonais e a do objeto de estudo - a forma espiral (Figura 1) (COSTA, 2014).

Figura 1: forma espiral

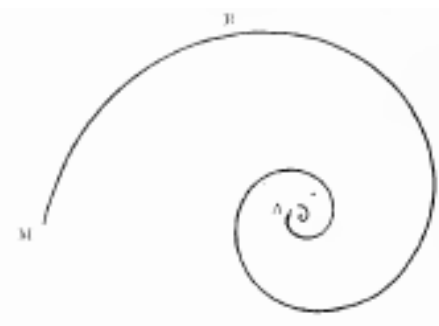

Fonte: COOK (1914)

Os exemplos de elementos da natureza com a essência da sua forma em espiral são alguns animais microscópicos e nebulosas no espaço. Em fenômenos da natureza, o padrão repete-se também como a rotação habitual de correntes de ar, que, no hemisfério norte, é da esquerda para a direita, enquanto, no hemisfério sul, é da direita para a esquerda. Furacões e tornados são produzidos pela reunião repentina dessas correntes de ar que se movem em direções opostas e o efeito do vento na areia produz um turbilhão de espirais, geralmente vistos em tempestades de areia, produzidos também em pequenas escala (COOK, 1914).

Em seres orgânicos, como nas plantas, espirais são observáveis a partir de sementes e células, como também em caules, flores e frutas. Em animais e no ser humano, a espiral segue todo o curso do desenvolvimento 
vital, do espermatozoide à estrutura muscular do coração, do cordão umbilical à cóclea do ouvido e na forma e estrutura de grande ossos do corpo.

Segundo Cook (1914), na natureza, a concha é o mais perfeito exemplo de espiral. A nautiluspompillius (Figura 2) ilustra perfeitamente a ideia de espiral logarítmica, cuja curva, segundo estudos e exames geométricos exatos do naturalista Canon Moseley, descobriu-se como essencialmente logarítmica, já que as espirais aumentam de largura em uma série sucessiva exata, cada uma das quais um múltiplo seguindo uma certa proporção.

Devido à curva logarítmica, a casca da concha não poderia possuir outra forma que não fosse a espiralar, conformando, nos exemplares examinados, uma simetria geométrica. Segundo o mesmo estudo, a forma desta casca seria produzida pela revolução do perímetro da figura formada pelo eixo da concha. No caso do nautilus, o animal que habita a concha empurra o opérculo (estrutura anatômica que encerra a concha de múltiplas espécies de gastrópodes) para a frente para depositar matéria adicional ao longo da margem inferior da concha, o que faz com que a elipse que gira em torno do seu eixo menor aumente em progressão geométrica, sem nunca mudar sua forma (COOK, 1914).

Figura 2: seção da nautiluspompilus.

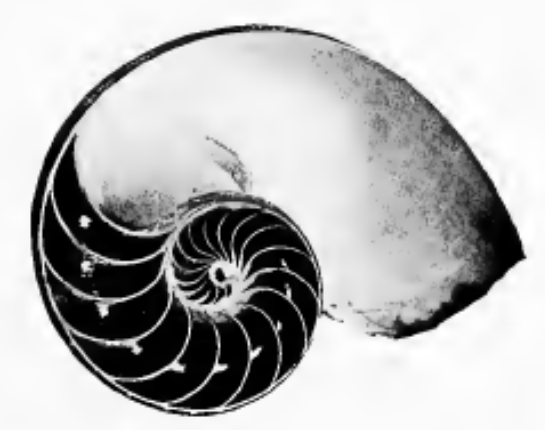

Fonte: COOK (1914).

A espiral logarítmica foi descrita pela primeira vez por Descartes (século XVII) e, mais tarde, investigada por Jacob Bernoulli (século XVIII), que a chamou spiramirabilis (ou espiral maravilhosa). A partir disso, Thompson (1917, p. 172) definiu a espiral como "uma curva que, continuando, a partir de uma dada origem, a aumentar o seu raio, simultaneamente diminui a sua curvatura, à medida que de tal ponto se afasta", além disso, seu processo típico é permitir um aumento do volume da forma, sem alteração notória das suas regras de crescimento. Segundo Costa (2014), por isso insere-se numa categoria chamada gnomónico(palavra de raiz grega que significa "o que indica" ou "que dá pra saber"), anteriormente referenciada por Aristóteles, por possuir a propriedade específica de ampliar sem sofrer nenhuma alteração durante seu crescimento. 
Uma das representações da espiral é baseada numa sequência de retângulos de proporção áurea, conceito grego que obriga o menor dos segmentos estar para o maior, assim como o maior está para a totalidade do segmento inicial, proporção que teve grande repercussão estética em diversos períodos da história, tanto em criações arquitetônicas, como nas artes em geral, tornando-se uma referência que implica forte harmonia estética (COSTA, 2014).

É relevante o fato de que o fascínio pela forma retangular atrai o olhar até mesmo do leigo por conta das relações matemáticas nesta ocultas, as quais, quando estudadas, podem tornar-se fonte de prazer para o matemático. 0 retângulo áureo, além de ser um formato economicamente útil, é uma figura esteticamente agradável (HUNTLEY, 1970).

Segundo Costa (2014), a geometria se aproximou da estética ao longo do século XIX, e, com as inovações no campo artístico no século XX, associou-se às ciências humanas, influenciando uma crescente experimentação nas artes. Essa relação resultou no modo de ver a beleza, como também em otimização funcional, e, como uma consequência do movimento moderno, favoreceu a reaproximação entre arte e natureza. Importantes teóricos, como Vitruvius (século I a.C.), definiram o que seria a proporção com base na sequência de retângulos áureos, conectando a necessidade de equilíbrio entre as partes do corpo e do edifício.

Um dos principais expoentes do modernismo, Le Corbusier, elaborou uma teoria geométrica na qual podia-se retomar um pouco aos princípios harmônicos de Pitágoras, já utilizados no Renascimento por Alberti e Palladio. 0 arquiteto criou seu próprio sistema de proporções, que pretendia ser a síntese dos princípios modulares de composição, baseando-se no corpo humano, na seção áurea e na série Fibonacci - sequência de números inteiros na qual, cada termo subsequente corresponde à soma dos dois anteriores (HUNTLEY, 1970) - o qual chamou de Modulor, para, mais tarde, aplicar conceitos relacionados à matemática em projetos arquitetônicos.

\subsection{Na arquitetura: o Museu Nacional de Arte Ocidental (1957-59)}

O sistema Modulor não ilustra o único exemplo do trabalho de Le Corbusier com proporção e formas geométricas. Moos (1988) defende que o arquiteto incorpora formas como partidos arquitetônicos, relacionando-as a propósitos específicos. Para o autor, identifica-se esse fenômeno em quatro tipos de projetos de Le Corbusier: o módulo de habitação em caixa, o museu em espiral, o estádio em forma de vaso (ou embarcação) e salas de reuniões triangulares.

Como pontua Moulis (2002), a aplicação da forma espiral como partido arquitetônico desenvolveu-se na obra de Le Corbusier através de uma série de estudos sob a forma de esboços realizados entre 1929 e 1965 (Figura 3). Como resultado, a evolução do modelo de espiral quadrado, 
primeiramente formulado para o $\mathrm{MCI}$, tornou-se um protótipo para os museus posteriormente construídos em Ahmedabad, Chandigarh e Tóquio.

Figura 3: Espiral em projetos de Le Corbusier, da esquerda para a direita: World Museum (1928-29); Pavillon de l’Esprit Nouveau (1936-37) e Museu do Crescimento Ilimitado (1939).
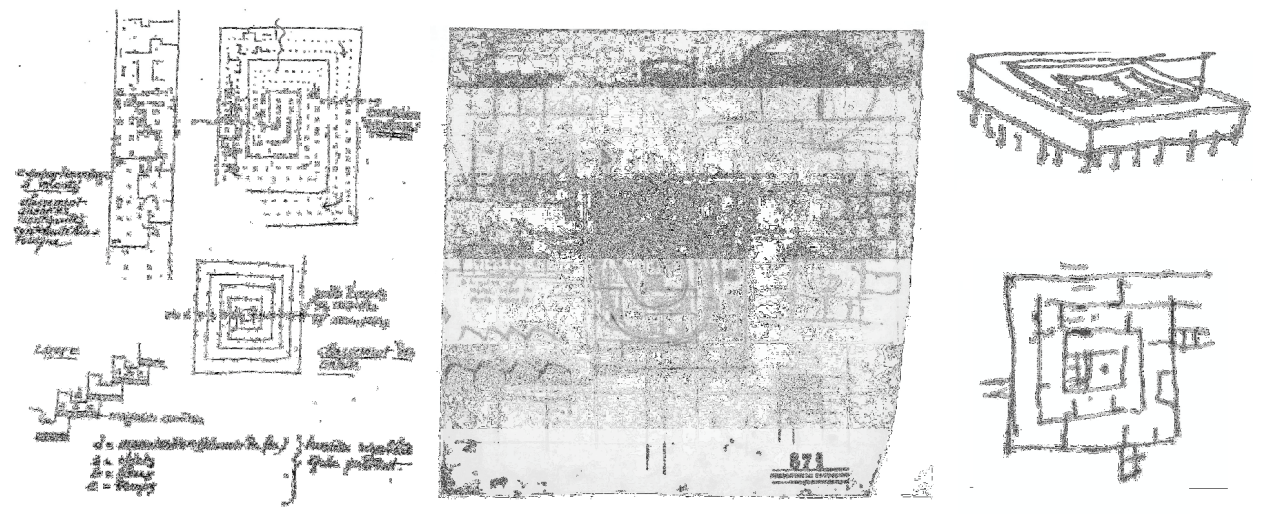

Fonte: ROLIM, AMORIM, JABORANDY (2018).

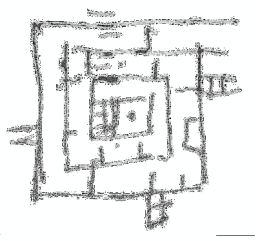

O MNAO foi originalmente projetado para abrigar e exibir a coleção Matsukata, do empresário, Kojiro Matsukata, ex-presidente da Kawasaki Shipbuilding Company, colecionador de um grande número de pinturas, esculturas e gravuras advindas de suas viagens ao Ocidente. Com a crise financeira de 1927, sua coleção foi vendida e, depois da Segunda Guerra Mundial, muitas das obras tornaram-se propriedade do governo francês, que as devolveu ao Japão em 1959 (Figura 4) (BOESIGER, 1936).

Prioritariamente em concreto armado e com uma área total de $17.369 \mathrm{~m}^{2}$, o edifício, de três pavimentos, tem seu corpo principal de galerias sobre pilotis, com o setor administrativo localizado ao norte da planta.

A organização geral do edifício é baseada em uma espiral inserida em um quadrado. 0 acesso dá-se pelo piso térreo, envolto em vedação em vidro e ladeado por pilares, sugerindo um percurso em espiral pelo restaurante, lojas e sala de estar ou ao salão principal, a chamada Sala do Século XIX, que funciona como um átrio de pé-direito duplo. Este átrio, semelhante ao que acontece no MCI, é iluminado por uma claraboia na forma de uma pirâmide envidraçada, que, voltada à direção norte, é suportada por vigas cruzadas, que a destacam espacialmente, gerando uma luz dramática e, ao mesmo tempo, funcional para o espaço de exposição.

Através da rampa, o visitante segue até a galeria superior, que envolve o átrio/galeria central de pé direito duplo, para o qual voltam-se varandas, partindo deste pavimento. Nesta galeria, predominantemente um espaço fechado, há quatro opções de contato com o exterior através de grandes aberturas ou escadarias. Por meio de trajetos lineares, o visitante é levado a três mezaninos independentes, que flutuam por sobre a galeria do piso superior. 
Figura 4: plantas baixasdo térreo, primeiro pavimento e mezanino,MNAO (1959).

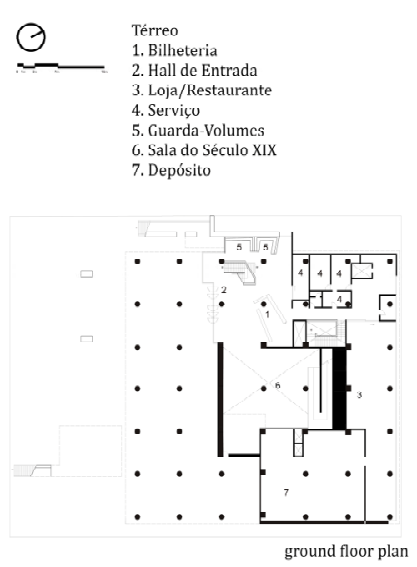

$$
\begin{aligned}
& \text { Primeiro Andar } \\
& \text { 1. Sala do Século XIX }
\end{aligned}
$$

Mezanino

1. Parte Superior da sala de exposição 3. Parte Superior da sala do século XIX 3. Varanda

Galeria de Illuminaşão
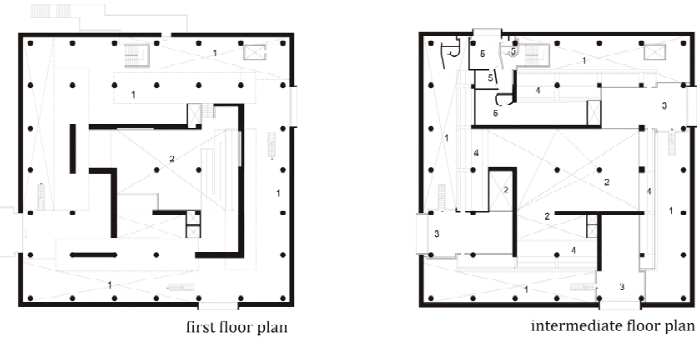

Fonte: elaborada pelos autores (LE CORBUSIER, 1946).

Para Le Corbusier, as cobertas são uma parte importante do edifício. No MNAO, além de claraboias, a coberta adquire diferentes formas e planos altimétricos, com lanternins que permitem a passagem de luz natural para o interior. Contudo, apesar das jardineiras, não é um espaço aberto ao acesso de visitantes.

0 arquiteto usa a espiral para sugerir tipos de circulação e reforçar o conceito de promenade, cuja ideia é a arquitetura enquanto um evento que se desdobra diante de um corpo que se move no espaço (MOULIS, 2002). Como no MCI, em Tóquio, a espiral define o passeio, sobrepondo-se a outro tipo de configuração em quatro eixos, como um cata-vento, que se sobrepõe à espiral. 0 cata-vento como circulação secundária é descrito por Le Corbusier como necessário para corrigir as tendências labirínticas que por ventura fossem provocadas pela circulação em espiral principal (Figura 5).

Figura 5: diagrama da proposta de percurso em espiral.

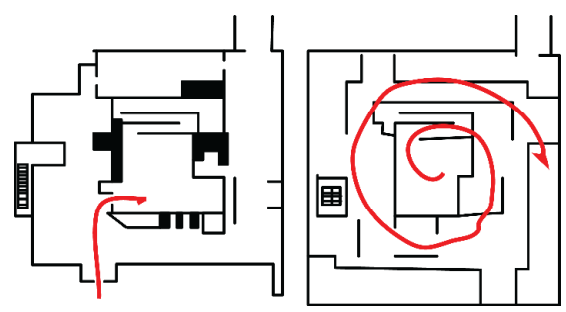

Fonte: elaborada pelos autores.

Quando o visitante sai da espiral, é possível experimentar diferentes visadas através dos quatro eixos para o exterior que enquadram o horizonte à arquitetura, trazendo mais complexidade a esta combinação de formas. Deste modo, o percurso é induzido por paredes paralelas, que garantem força 
ao passeio arquitetônico, apresentando meios de sair da espiral e sugerindo outra rota de passeio. Esse espaço, Moulis (2003) categoriza como axial, por se estender segundo o eixo longitudinal (Figura 6).

Figura 6: diagrama de espaço espiral e axial MNAO (1959).

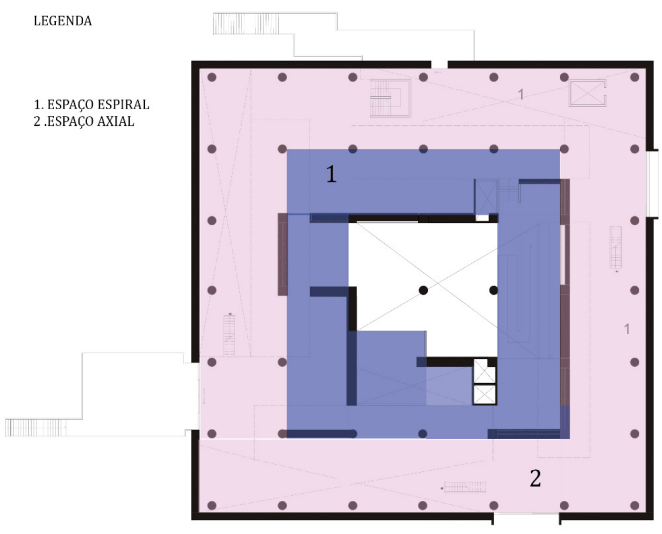

Fonte: elaborada pelos autores.

A forma espiral estabelece uma relação de descoberta exploratóriado visitante para com o museu, uma vez que o horizonte se estabelece à medida que o espaço vai sendo revelado. Percebe-se, portanto, queeste recurso foi utilizado para induzir uma experiência mais única, que aguça a curiosidade do visitante para com o espaço. Ao mesmo tempo que parece tratar-se de um espaço sem fim, o usuário desenvolve uma espécie de ânsia por vislumbrar o exterior.

Uma vez que a espiral é inserida no desenho arquitetônico, sua forma altera profundamente as propriedades configuracionais do espaço, pois, neste caso, se assemelha a um labirinto, uma vez que não permite o visitante vislumbrar claramente o que está adiante, condição essencial a um labirinto tradicional, que aqui é parcialmente interrompida. E são essas interrupções nas barreiras físicas limítrofes da espiral que proporcionam ao visitante a vontade de alcançar o horizonte. A seguir veremos justamente como essa espacialidade pode ser vista do ponto de vista analítico no MNAO segundo ferramentas de análise sintática.

\section{ANÁLISE DO ESPAÇO}

\subsection{Materiais e métodos}

Foram analisadas as plantas do térreo, do pavimento superior e do mezanino do MNAO. As planta baixas, de nossa autoria, foram geradas com base em documentos disponíveis na obra Le Corbusier Ouvre Complète, 19381946. Vale ressaltar que, mesmo buscando a maior precisão possível com relação a esta fonte primária, os desenhos gerados refletem nossa interpretação do material consultado. 
Para elaboração destas plantas, mapas e grafos para a análise sintática, foi utilizado o software AutoCAD para produzir as plantas baixas, o JASS para gerar o grafo justificado e a plataforma Depth Map X (TURNER, 2007) para gerar mapas convexo e axial e o grafo de visibilidade.

\subsection{Uso da Sintaxe espacial na análise}

$\mathrm{Na}$ abordagem teórica da sintaxe espacial, entende-se que as pessoas movem-se em linhas axiais, interagem em espaços convexos e veem campos visuais, os quais mudam à medida que estas movimentam-se em ambientes construídos. A partir da descrição dos espaços com base nos mapas e grafos, é possível investigar a relação entre comportamento social e configuração espacial (Figura 7) (AL SAYED, 2014).

O mapa axial descreve o movimento, ou seja, reduz os espaços a linhas mais longas acessíveis que cobrem os espaços convexos em um mapa, ajudando a prever a movimentação de pedestres. 0 mapa convexo representa as relações de adjacência dos espaços, representando a hierarquização destes. Ambos foram utilizados para analisar conectividade e integração, que, quando altas, indicam como é fácil para um indivíduo em uma posição no espaço entender a estrutura geral do lugar (ou sistema espacial).

Figura 7: mapas convexos e axiais, MNAO (1954).
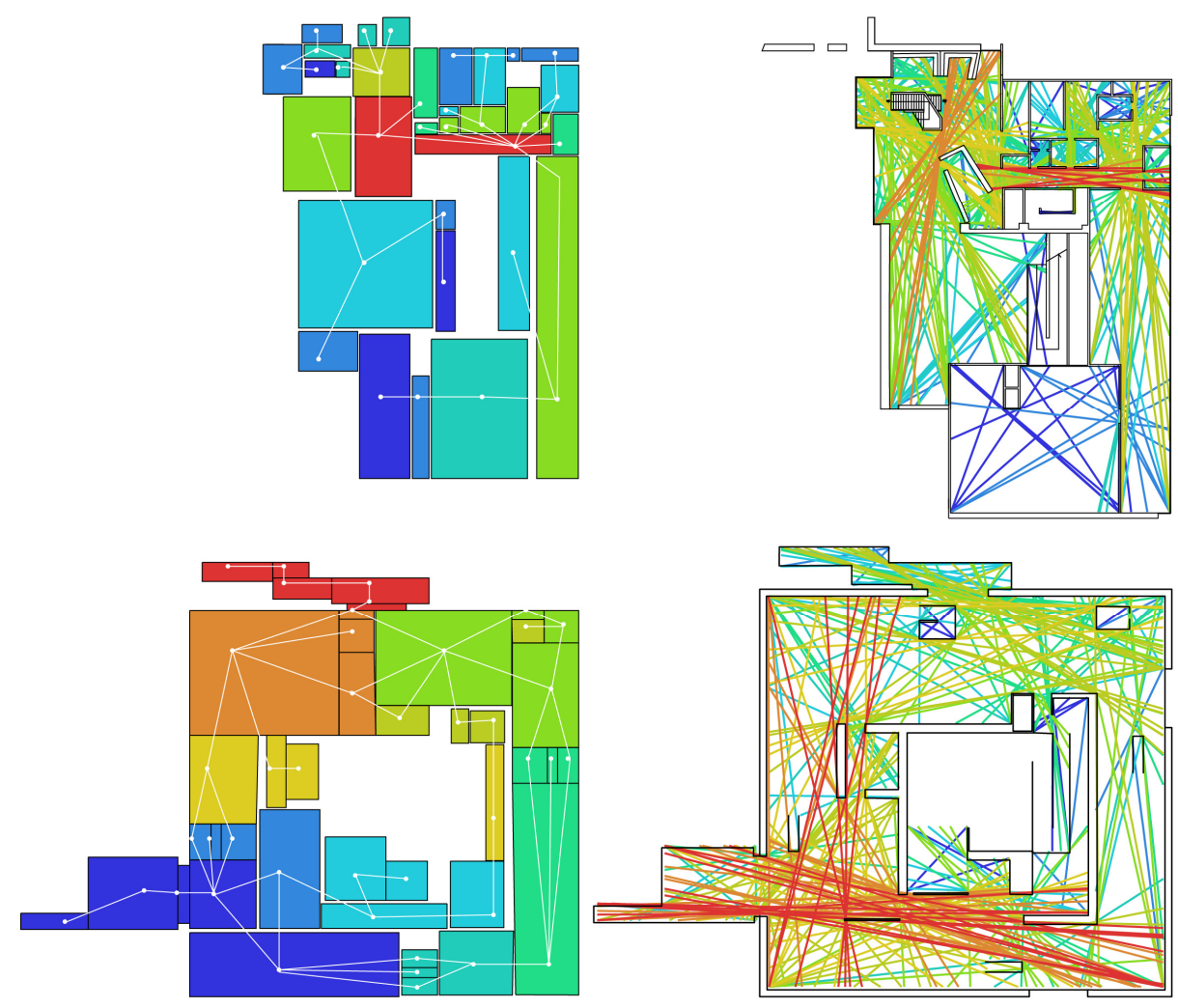

Fonte: elaborado pelos autores. 
Os grafos justificados são uma forma de analisar graficamente, através de uma árvore ramificada, a assimetria e a profundidade de um sistema espacial. No grafo, os pontos representam os espaços e, as linhas entre estes, as conexões dentro do sistema. Começando com um ponto base (ou raiz), a cada nível de profundidade, os pontos organizam-se horizontalmente, afastando-se verticalmente da raiz, de modo que o topo do grafo representa o espaço mais profundo dentro do sistema (HILLIER, 1989). Destacamos em vermelho no grafo abaixo os espaços mais relevantes analisados neste estudo, as galerias.(Figura 8)

Figura 8: grafo justificado do MNAO (1954), destacando galerias, átrio e balcões.

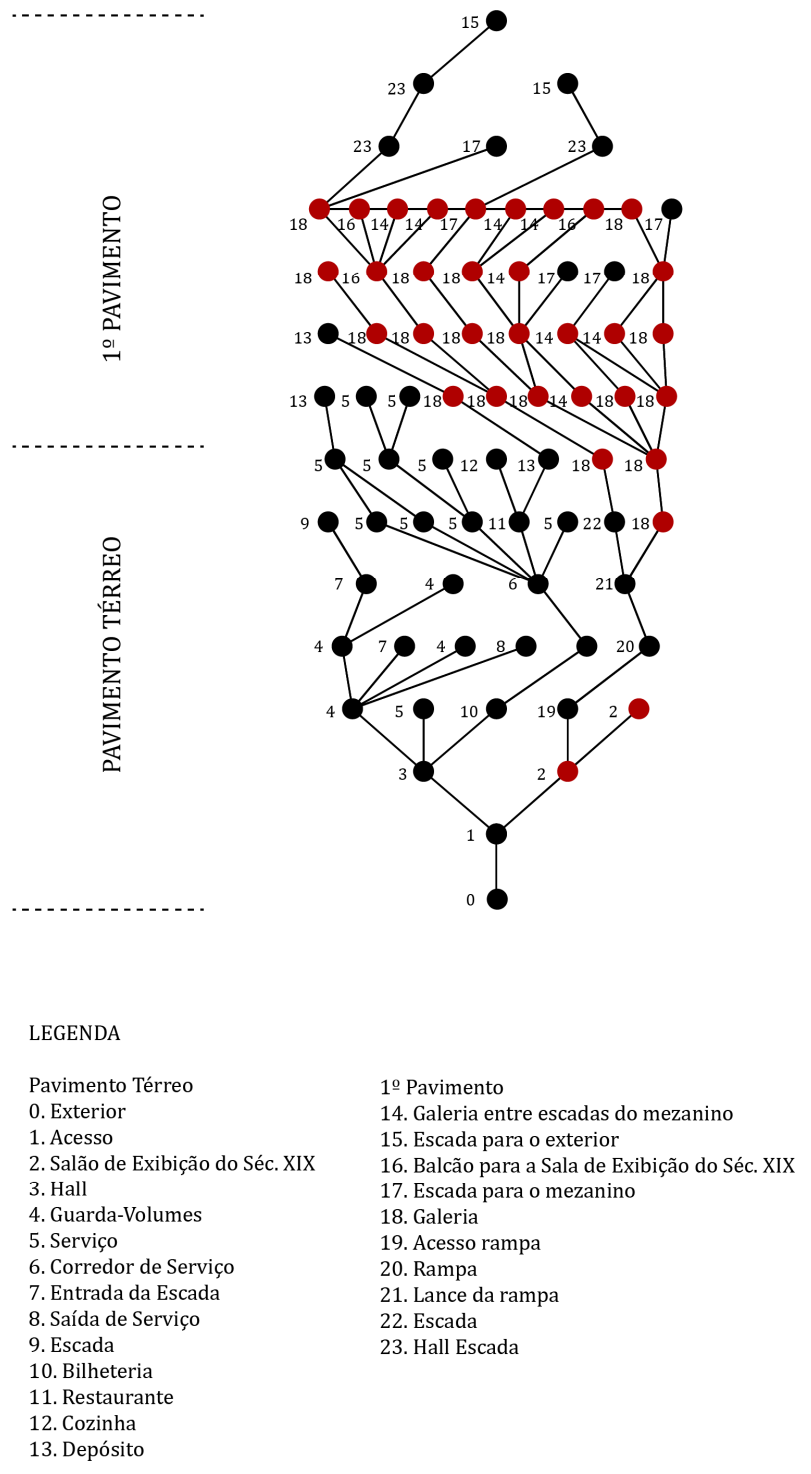

Fonte: elaborado pelos autores. 
0 grafo de visibilidade (VGA) foi usado para analisar as propriedades visuais dos layouts, especialmente a integração, que mede o quão profundo ou superficial é um espaço em relação a outros, indicando aqueles que funcionam como um ponto de encontro natural de pessoas (Figura 9) (ROLIM, AMORIM; JABORANDY, 2018).

Figura 9: grafo de visibilidade MNAO (1954).
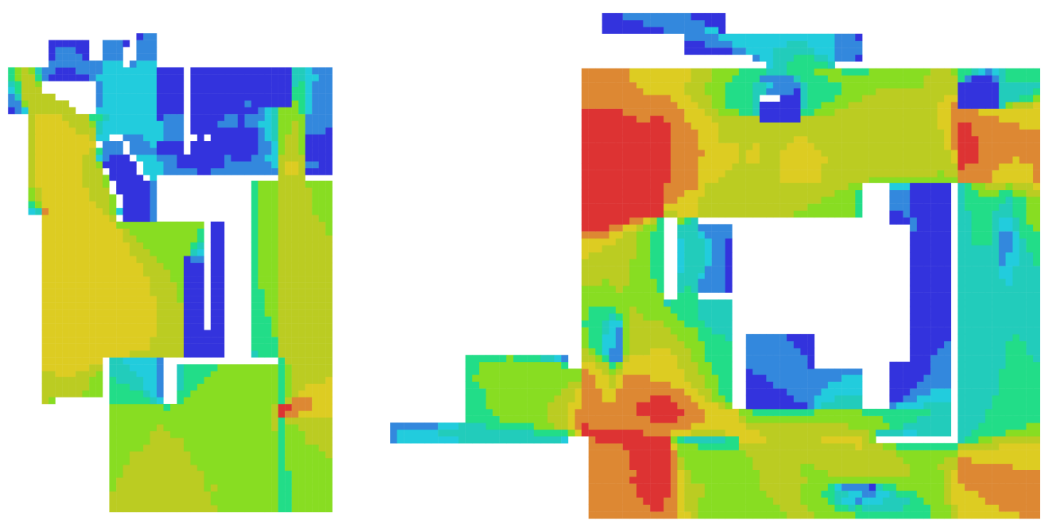

Fonte: elaborada pelos autores.

\subsection{Discussão de resultados}

Seguindo o conceito do MCI, o museu projetado por Le Corbusier em Tóquio foi uma evolução da ideia ali implantada, convertendo-se em um edifício de bem maior complexidade programática, incluindo áreas de serviço com acesso restrito, loja, restaurante, sala de estar, o que, consequentemente, influenciou as relações espaciais no sistema.

Considerando as galerias, o museu dispõe de 31 espaços convexos. No térreo, o átrio é um tipo de galeria configurada por 2 espaços convexos. As galerias do pavimento seguinte, o principal, são mais complexas e com espaços convexos maiores nos quatro eixos, evoluindo na espiral. Através do mapa, também podemos perceber que os espaços próximos a possíveis saídas e acessos, e que indicam rotas alternativas, são os mais integrados. É notável que a maioria dos espaços de galeria do MNAO estão no piso principal, refletindo a intenção do arquiteto de colocar praticamente toda exposição no mesmo plano horizontal. Os espaços mais conectados estão ao redor do grande salão, exceto no balcão/sacada, de onde o usuário pode ver o grande átrio de cima, onde se caracteriza, assim, como um ambiente de permanência (Figura 7).

Hillier (1986) identificou a existência de quatro tipos de espaços de acordo com a conexão com outros espaços do sistema: o tipo "A" são espaços com um único acesso (ou "sem saída"); o "B" conecta-se a dois ou mais espaços, mas não faz parte de nenhum anel de circulação; o "C" está normalmente em um anel e o "D", em dois ou mais destes anéis. Ainda 
referente a esta classificação, o autor ressalta que um aumento global no número de espaços tipo "D" minimiza a profundidade do sistema, o tornando mais integrado, enquanto que um aumento global na quantidade de espaços "B" e local de espaços "C", levam a sistemas mais segregados (ROLIM, AMORIM e JABORANDY, 2018). Além disso, segundo Amorim e Lins Filho (2014), espaços "B" e "C" são mais sujeitos ao controle de acesso e saída e, juntamente com os espaços "D", são mais propícios ao movimento, enquanto os espaços " $\mathrm{A}$ " tendem a configurar-se mais frequentemente como locais de permanência (Figura 8).

No grafo justificado, foram destacados, em vermelho, os espaços das galerias, o átrio, os balcões e as galerias entre as escadas do mezanino. 0 átrio, localizado no térreo, está em uma posição relativamente rasa no sistema, mas representa o começo da exposição, à medida que o visitante, a partir daí, começa a conhecer as demais galerias. 0 primeiro pavimento, então, possui espaços bem conectados, visto que neste predominam espaços tipo "C" e "D". As galerias no primeiro pavimento formam alguns anéis de circulação, que permitem que o visitante mova-se ao redor da Sala de Exibição do Séc. XIX por diferentes caminhos. Neste sistema, até mesmo os locais que tendem a gerar uma maior permanência, ou seja, aqueles com apenas uma saída, podem ser acessados por diversos pontos, configurandoos como integrados às galerias (Figura 8).

Em relação à movimentação, através do mapa axial podemos perceber que há um grande eixo na entrada da exposição, no térreo (Figura 7). Por conta de requisitos funcionais, percebe-se que, ainda no térreo, o corredor de serviços é um grande eixo de circulação dentro do sistema. No pavimento superior, prevê-se grande movimentação de visitantes, principalmente onde há maiores separações dentre paredes paralelas e septos, justamente onde se localiza o maior eixo axial, a oeste da planta. Neste pavimento, o espaço que possui menor eixo axial é o volume que saca acima da Sala de Exibição do Séc. XIX, portanto,menos provável de abrigar movimento intenso de pessoas (Figura 10). 
Figura 10: na ordem, galerias e balcão acima do átrio.

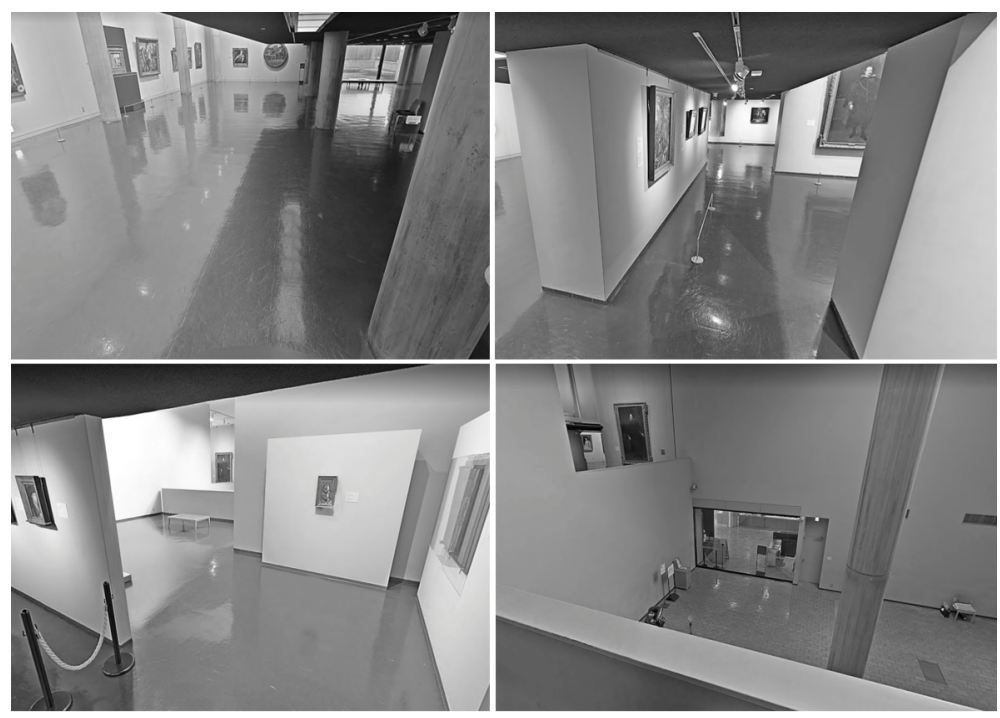

Fonte: GOOGLE EARTH-MAPAS. Consulta realizada em 01/05/2019.

Quando analisado o gráfico VGA do MNAO (Figura 9), observa-se que um visitante situado na Sala do Século XIX possui uma grande visibilidade, se comparada aos demais ambientes. Assim que o visitante acessa o museu, vê o grande salão, e naturalmente, guarda seus volumes na recepção para começar o passeio pela Sala do Século XIX. Após isso, continuando o percurso, a rampa é um elemento com pouca visibilidade, mas que marca o começo da espiral. No pavimento seguinte, que é o principal por possuir várias galerias, há uma grande variação dos tipos de campos visuais. Há quatro eixos que possibilitam a chegada e a visão do exterior do edifício, de onde o usuário consegue enxergar e perceber a profundidade do espaço, enquanto que, em outras situações, este último possui um visão limitada, o que, supomos, poderia levar a um certo tipo de ânsia por encontrar o fim do quasi labirinto.

Vemos que na análise de visibilidade, a ideia do recurso utilizado é reafirmada: quando posicionados no espaço espiral, os visitantes estão livres para se concentrar nas obras de arte e, quando não, experimentam a extensão do espaço para o horizonte e a conexão com o exterior. Não se trata apenas da linha do horizonte desaparecendo e aparecendo para o visitante, afinal a própria organização do museu parece tornar o horizonte mais atraente e desejável do que a experiência que, de outra forma, poderia resultar mais próxima àquela que normalmente ocorre em um labirinto.

\section{CONSIDERAÇÕES FINAIS}

0 estudo aqui apresentando ratifica a intenção do arquiteto em sugerir o percurso espiral no MNAO (1954), uma vez que o uso desta lógica de organização espacial contribui para que o museu conforme um sistema complexo, quando se trata de sua composição de espaços convexos. 
Independentemente das obras de arte inseridas no espaço, o que não foi possível aferir nesta presente análise, as galerias variam significativamente em tamanho e forma, oferecendo diferentes campos visuais e experiências.

Percebe-se que, durante o percurso, os visitantes podem seguir a lógica da espiral ou desconectar-se desta por intermédio de conexões com os mezaninos, o que também permite que estes usuários tenham uma visita mais exploratória, na qual, mesmo havendo uma sugestão de rota principal, há a oferta de outras possíveis trajetórias através dos mezaninos sobrepostos.

Possuindo apenas quatro pontos que permitem contato ao exterior, $\mathrm{o}$ sistema, como um todo, gera diferentes mudanças nos campos visuais dos visitantes. Esta condição nos leva a crer que a intenção do arquiteto era a de que, a cada volta ao redor do ponto central do edifício, o visitante ou pudesse, de fato, olhar para o exterior (saindo um pouco do ambiente construído do edifício), ou encontrar-se novamente na espiral infinita, o que lhes informaria que estariam prestes a iniciar outra virada na espiral, conhecendo o espaço pouco a pouco. Este recurso parece ter sido propositadamente empregado para quebrar a sensação enfadonha que existiria na repetição sequencial da forma espiral.

Sabemos que a configuração espacial influencia no movimento dos usuários, o que afetaria sua percepção acerca do ambiente. No espaço do museu com configuração mais próxima à labiríntica, entre barreiras e com pouca visibilidade do espaço, o usuário provavelmente sentir-se-ia mais perdido, mas também, por sua condição enquanto espaços “C” e " $D$ ", estes tenderiam a proporcionar um maior movimento de pessoas. Observamos ainda na análise que os possíveis encontros de visitantes dar-se-iam nos quatro eixos que marcam a conexão com o exterior e que a visibilidade no espaço chamado axial é verdadeiramente mais limitada, sugerindo que, em um só espaço, poderia haver experiências diversas.

Por fim, acreditamos que, ao buscar entender o caso aqui apresentado enquanto uma emblemática solução projetual cunhada no contexto da arquitetura moderna, isto possa estimular, no âmbito geral, novos estudos sobre geração da forma aplicados à arquitetura e ao desenho, e quem sabe, levar a alternativas com potencial para gerar espaços propícios a visitas mais exploratórias e menos entediantes em espaços de museus na contemporaneidade.

\section{REFERÊNCIAS BIBLIOGRÁFICAS}

AMORIM, L.; LINS FILHO, M. C. Padrões espaciais de moradia: o apartamento contemporâneo segundo seus espaços-tipo. In: Anais do Encontro Nacional de Tecnologia do Ambiente Construído, 2014. v.1. p. 2206 - 2215. 
BOESIGER, Willy. Le Corbusier 1910-65. Suécia: Birkhäuser Architecture, 1999. $351 \mathrm{p}$.

BAKER, Geoffrey H. Le Corbusier: uma análise da forma. 1998. ed. São Paulo: Wmf Martins Fontes, 2002. 399 p.

COOK, Theodore Andrea. The curves of life: an account of spiral formations and their application to growth in nature, to science and to art. 1914. ed. Londres: Constable and Company Ltd, 1914. 479 p.

COSTA, Luís Alves da. Da geometria à estética através das formas naturais. 2014. ed. Portugal: Edições Humus, 2014. 130 p.

GOOGLE EARTH-MAPAS. Disponível em: <http://mapas.google.com>. Acesso em: 01 maio 2019.

HUNTLEY, E. A. A divina proporção: um ensaio sobre a beleza matemática. 1970. ed. Brasília: Editora Universidade de Brasília, 1985. 178 p.

HILLIER, B.; HANSON, J. The social logic of space. Cambridge: Cambridge University Press, 2003. 281 p.

HILLIER, Bill. Space is the machine: a configurational theory of architecture. Cambridge: Cambridge University Press, 1986. 355 p.

334-45, p. 5-21. . The Architecture of the Urban Object. In: Ekistics, v. 56, n.

BOESIGER, Willy. Le Corbusier oeuvre complete 1957-1965. Zurich: Les Editions D'Architecture, 1946.

MO0S, Stanislaus von. Le Corbusier: elements of a synthesis. Cambridge: MIT Press, 1988, 379 p.

MOULIS, Antony. Le Corbusier: the museum projects and the spiral figured plan. Takhar - Afeganistão: Celebrating Chandigarh Ahmedabad. Ahmedabad: Mapin, 2002. 355 p.

.Le Corbusier's horizon: technique and the architectural plan'. Architectural Theory Review, v. 8, n. 2, 2003. p. 134-142.

ROLIM, A.; AMORIM, L.; JABORANDY, M. The galleria progressiva in the Solomon R. Guggenheim Museum and the Museum of Unlimited Growth. In: International Symposium Formal Methods in Architecture and Urbanism: book of abstracts. Portugal, CESAP - Cooperativa de Ensino Superior Artístico do Porto, v. 4, abr. 2018.

THOMPSON, D'Arcy Wentworth. On growth and form: the complete revised edition. 1917. ed. Estados Unidos: Dover Publications, 1992. 1116 p.

TURNER, Alasdair. New Developments in Space Syntax Software. In: Proceedings of Workshop on New Developments in Space Syntax Software. Istambul: ITU Faculty of Architecture, 2007, p. 1-51. 